\title{
Smart Safety Gadgets for Women: A Survey
}

\author{
Mona Chaware*, Dipali Itankar, Diksha Dharale, Divya Borkar, Shraveen kumar Pendyala, Mrudula Nimbarte \\ Department of Computer Science Engineering \\ J.D. College of Engineering and Management, Nagpur, Maharastra
}

\author{
D.O.I - 10.51201/12481 \\ https://doi.org/10.51201/12481
}

\begin{abstract}
Sexual violence against women has become one of the most important social security problems in India. None of the existing humanitarian mobile application exactly contains the features that a victim need in times of danger or immediately after victimized. Industries and other sectors of the commercial market, it is a necessity for women to travel at late hours and visit the distant and isolated location as a work region. However the expensive part of their increase in assault and attack against women posing a threat. The Defense isn't the only measure that can help against this increasing abuse. A security solution that creates a sense of safety among women needs to be devised. In an instance of an attack, it is largely reported that women are immobilized. There is a need for simpler safely solutions that can be activated as simply as by pressing a switch and can instantly send out alerts to the near one of the victims. "When safety and security are concerned", a smartphone becomes a powerful tool to prevent violence against women. Keeping these in mind, apps have been developed which is dedicated to providing relief to the person in trouble.
\end{abstract}

Keywords: GPS and GSM Module, hardware device, mobile application, gadget, safety, message alert

\section{INTRODUCTION}

In recent years, the number of occurrences of events related to women harassment has grown with ever-increasing rate, it is beyond doubt that women are not safe outside particularly Maharashtra and in other State according to the national crime record bureau $\{\mathrm{NCRB}\}$ harassment at the workplace at public transport and other places among other states. Maharashtra is in third position with 2910 cases. There occur many such heinous events against women's development in a different region. In most cases, rape cases do not justice due to the lack of timely identification of guilty persons thus it accelerates the rate of rape incidents in society. To overcome the drawbacks of women's safety applications, an algorithm is to develop ed that works similarly like a security application. The world of intelligence always deals with the updating concepts day-by-day. The intellectual ability of human beings is increasing vigorously, whereas safety concerning ever-increasing updating technology (IoT). In recent various Mechanism viz. Network mechanisms, Mobile mechanisms, Helpline numbers, and various systems were designed, to overcome the women in a critical situation, but the accuracy with those mechanisms is less which results in many crime situations. Every system has different techniques to measure the security of the situation. The best way to curtail due to your probability of becoming a dupe of violent crime (robbery, sexual assault, rape, domestic violence) is to be recognized, defense, and lookup resource to help you out at hazardous situations.

\section{PROBLEM STATEMENT}

All the safety devices have been used some applications which have to be installed on our mobile phone. But during, some kind of emergency, it is somehow difficult to carry the phone, unlock it and then open the particular application. During a case of kidnapping, the kidnapperfirst snatches the mobile phone of the victim. These mobile applications need more time due to procedure or sometimes it is not possible to do due to nervousness. There are some wearable devices, which need some special treatment, like a smart foot device, it needs four times tapping of footwear, then it sends a message to the mobile where a particular application is installed. Some devices need more time for activation or some Android apps should be installed on our mobile phone. Sometimes the module does not work due to some technical issues. So such problemscan be solved easily by makingthis type of device.

\section{LITERATURE REVIEW}

In [1] a design and implementation of women auspice system by utilizing GPS and GSM has examined only the present situation. The system is portable and the system but it is complicated. The amount of batteries is used in the above system and three pushbuttons are implemented.

In [2] an Android and Bluetooth low energy device based safety system are much more expensive and they develop an Android application, the situation is there where the women are immobilized in such a situation so they are unable to use it. The system additionally gives voice acknowledgment include in Android versatile.

In [ 3] a self-defense device with GSM alert and GPS tracking with fingerprint verification for women safely device has the only activation through fingerprint, electric shock producing circuit, design a small button-shaped device which will be handy and easily portable. 
In[4] a smart intelligent system for women and children security systems work on the pressure switch and portable device. Instantly the pressure sensor senses the pressure and conventional SMS with location send to their parent's guardian.

In [5] a smarisa : a raspberry pi based smart ring for women safely using the IoT device feature implemented in the ring. They use a raspberry pi camera, buzzer, and button to activate the services.

The model is servedas a safety device and alerting device. the devices are mostly the Android Apps or some Hardware devices.

In [6] All-in-one-system is also an embedded system that used an application unit. It comprises all the tools which help for the safety purpose.

In [7] Seftipin, is one of an android application, which uses a safety score for knowing which place is safe or which place is not safe.

Sometimes it is unable to give information about the place or the app is not working.

In [8]. Women Safety Device and Application-FEMME The model proposed in the paper is consists of both application and hardware units. When the emergency button of the device is triggered once, the GSM sends the location of the victim to the police. If the emergency button is doubleclicked, the system starts recording the audio and also sends the location of the victim.

If the emergency button is long pressed GSM sends a message and calls to the police. Using a GPS module, the location of the victim is traced. An audio recorder is used to record the audio at the incident. The hidden camera present in rooms can be detected using a hidden camera detector using the RF signal.

In [9]. AVR Microcontroller Based Wearable Jacket for Women Safety The paper has proposed a portable device that is placed in a jacket. It consists of a switching unit, GPS Module, GSM Module, LED Module, and Buzzer Module.

In [10] A Mobile-Based Women Safety Application (I Safe Apps) The paper is developed an android application to help women. Application has six options they are Add guardians, SOS, Fake call, Video call, First aid, and Instructions.

By clicking on the option "Add guardians" it takes to the other page and it has two options they are "Add from contacts", "Add new contacts". By clicking on Add from contacts application takes information from phone contacts.

If Add new contacts are selected then it allows us to enter the contact name and contact number by ourselves. By touching the SOS option call is made to emergency contacts and the location of the person is sent through the message.

In [11] Role of Facial Image, Analysis is an android application which is based on facial image analysis has given a good knowledge about the problems and further has focused on challenges associated with the problem. Various factors such as race, gender, age, expressions, etc. are identified as factors that affect the performance of the system.

So, it is very important to collect datasets to cover the complete problem. Besides, the dataset should have no variations in other factors such as lighting conditions, head pose, and occlusions. The complete comparative analysis is also presented for datasets required for these applications.

\section{PROPOSED SYSTEM}

Women's security is a basic issue in this day and age and it's particularly required for each person to act over such an issue. The "The Smart Safety Gadget for Women" is the project which will benefit the women's safety. Here we are going to implement a system that can easily be carried out by each woman.

The proposed system contains a "Raspberry-pi Zero W" which is flexible and compact as possible with mini connectors and It is a wireless LAN and having Bluetooth. Raspberry pi-0 W supports mini connector and adds easily. Basically, it is a mini-computer that has a small operating system Linux. Along with that System also have a Global Positioning System.

The system proposed for the abnormal state of security to the lady. These days, women are confronting a ton of issues in the general public. They need security which doesn't have any proviso in it. The system is managed through Bluetooth or Wi-fi connection.

As connecting Bluetooth or Wi-fi the system goes under process and it sends message alert $\&$ calls to the respective number saved in the database. Along with that the system utilizes the Global Positioning System (GPS) to discover the location/area of the person. The data of a person's location given by the gadget can be seen on Google maps by utilizing the Internet. 


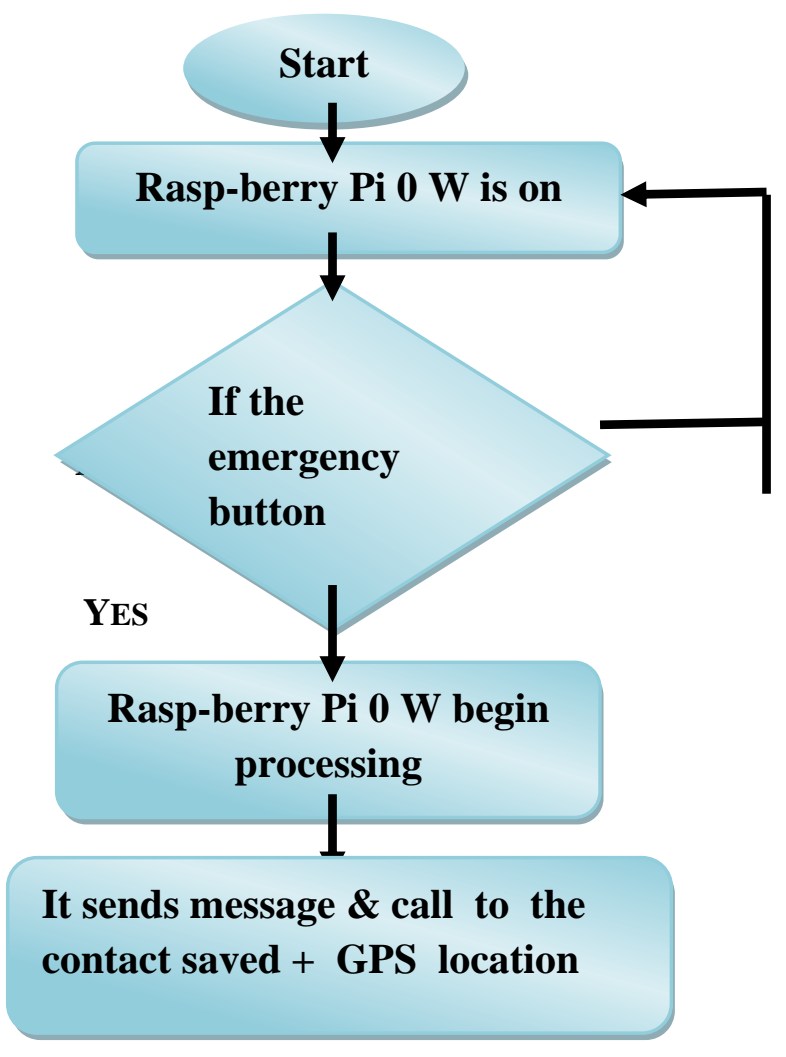

\section{CONCLUSION}

Women's security is a basic social issue in this day and age. Through this paper, we intend to advance a proficient and helpful security gadget for women. The proposed plan can deal with some basic issues looked by women. It can be concluded that through the systems women's safety is properly protected and they do not feel alone. The research has done a comparative analysis of different approaches for women's security. Each approach has its unique features to provide security for women. So, the future work should have the key concern of includingunique features from different approaches into the single system and making the device compact in size so it will be easy to carry.

\section{REFERENCES}

[1] Animal Islam, Mohammed RebuildHusain, Md. Anisuzzaman, sikder Sunbeam Islam, Abu Jafar: 'Design and Implementation of Women Auspice System by Utilizing GPS and GSM', International Conference on Electrical, Computer and Communication Engineering(ECCE), IEEE 7-9 Feb. 2019.

[2] P. Saikumar, P. Bharadwaja, Dr. J. Jabez: 'Android and Bluetooth low energy device based safety system'. Proceeding of the Third International Conference on Computing Methodologies and Communication, IEEE Xplore (ICCMC)2019.

[3] Shaista Khanam, Trupti Shah: 'Self defense device with GSM alert and GPS tracking with fingerprint verification for women safety'. Third International
Conference on Electronics Communication and Aerospace Technology(ICECA), IEEE Xplore, 2019.

[4] Prof. Sunil K Punjabi, Prof. Suvarna Chaure, Prof. Deepti Reddy: 'Smart Intelligent System for Women and Child Security'. 978-1-5386-7266-2/18, IEEE, 2018.

[5] Navya R. Sogi, Priya Chatterjee, Nethra U, Suma V: SMARISA: 'A Raspberry $P i$ based smart ring for women safety using IoT'.International Conference on Inventive Research in Computing Applications(ICIRCA), IEEE Xplore, 2018.

[6] Deepak Sharma Abhijit Paradkar 'All in one Intelligent Safety System for Women Security'. Vol 130 No.11 November 2015

[7] Ravi Sekhar Yarrabothu, Bramarambika Thota, 'ABHAYA: AN ANDROID APP FOR THE SAFETY OF WOMEN', Annual IEEE India Conference (INDICON), 2015.

[8] D. G. Monisha, M. Monisha, G. Pavithra, and R. Subhashini," Women Safety Device and Application FEMME". Vol 9 (10), Issue March 2016.

[9] Daniel Clement, Kush Trivedi, Saloni Agarwal, Shikha Singh 'AVR Microcontroller Based Wearable Jacket for Women Safety'.

[10] Dr.Sridhar Mandapati, SravyaPamidi,

SriharithaAmbati 'A Mobile-Based Women Safety Application(I Safe Apps)', IOSR-JCE, eISSN:22780661, p-ISSN:2278- 8727, Volume 17, Issue 1, VerI (Jan-Feb.2015)

[11] Mrudula Nimbarte, $K K$ Bhoyar, "Role of Facial Image Analysis: Various Attributes and Application", IEEE International Conference on Engineering and Technology Systems (ICET), Vol. 1, pp 28-32, 2016 
Table 1: COMPARATIVE ANALYSIS FOR THE DIFFERENT SECURITY DEVICE

\begin{tabular}{|c|c|c|c|}
\hline $\mathbf{S} \mathbf{N}$ & $\begin{array}{lllllll}\mathbf{D} & \mathbf{E} & \mathbf{V} & \mathbf{I} & \mathbf{C} & \mathbf{E} & \mathbf{S}\end{array}$ & T E C H N O L O G Y & 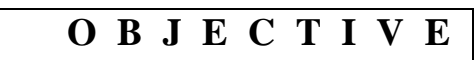 \\
\hline 1 & Design and Implementation of Women Auspice System by Utilizing GPS and GSM & Hardware Device & $\begin{array}{l}\text { Utilize GPS \& GS M } \\
\text { examine the present situation }\end{array}$ \\
\hline 2. & Android and Bluetooth low energy device based safety system & A n d r o i d A p p & The system gives voice acknowledgment \\
\hline 3 & Self-defensederise with GSM alet and GPS tracking with fingerpint verification for women satety & Hardware Device & Send message and GPS location through fingerpint scanning \\
\hline 4 & Smart Intelligent System for Women and Child Security & Hardware Device & Send SMS and location Using a pressure sensor the \\
\hline 5 & A Raspberry Pi-based smart ring for women s & GPS module & Sends alert and location to cho \\
\hline 6 & All in one Intelligent Safety System for Women Security & Embedded system & Comprises of all the necessary helping tools \\
\hline 7 & $\mathrm{~A} \quad \mathrm{Y}$ & A n d roid A p p & Send a message with location co-ordinate \\
\hline 8 & Women Safety Device and Application FEMME & ARM, Android App & Sendsinstant locationwitha distress messageto thepolicepresettumbers \\
\hline 9 & AVR Microcontroller Based Wearable Jacket for Women Safety & Hardware Device & send location \& SMS By pressing the buzzer \\
\hline 10 & A Mobile-Based Women Safety Application & A n d roid & Send location using SOS call \\
\hline
\end{tabular}

